consumption for this manufacture. There are 4 plants in the Cnited States producing acetone for the market and within the past week ground has been broken in Pennsylvania for a $5^{\text {th }}$ plant. There is but one plant operating in Canada to our knowledge.

Ten years ago the steel industry consumed by far the major percentage of charcoal produced. This percentage, however, has decreased considerably, owing to the mproved methods for steel production. Many industries such as cutlery and car wheel manufacture demanded charcoal iron, but in these and many other instances coke iron has been substituted. This falling off in the proportionate use of charcoal in iron production has been made up in an increased domestic demand. Charcoal is now sold in small paper sacks in many cities for use both in hotels and private families.

The production of crude wood alcohol amounts to between I0,000,000 and I I, 000,000 gallons per year, and of course it has innumerable uses, including those of the paint industry which is the largest single user.

Space will not permit, in a general article such as this, of going into details regarding production and markets of the other products such as formaldehyde, creosote, etc., which are directly or indirectly derived from hardwood distillation.

\section{DISTRIBUTION OF PLANTS}

Although not in agreement with any published figures, we place the distribution of distillation plants as follows:

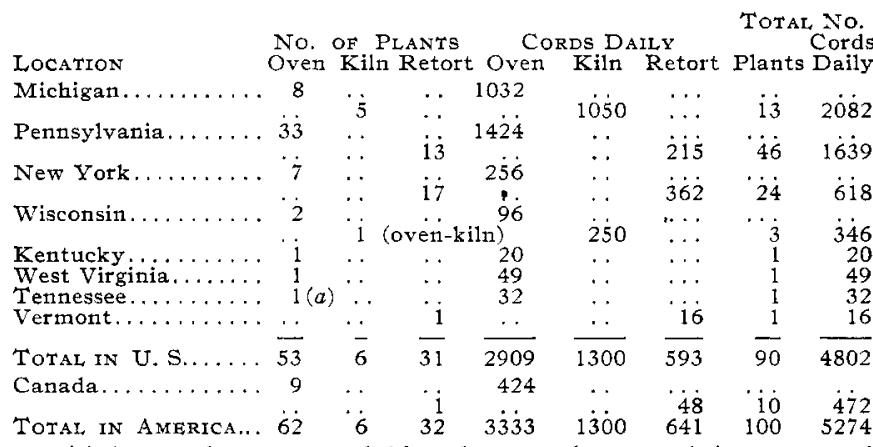

(a) A recently constructed 16 -cord retort plant now being converted into an oven plant.

These figures will mean more if we remember that 5,000 cords of wood represent a pile $4 \mathrm{ft}$. high 52 in. wide and 7.5 miles long weighing when seasoned approximately 10,000 tons, thus showing the importance and size of the industry in this country.

\section{CONCLISSION}

It will be evident that the chief economic drawback in the present manufacture is the fact that most of the plants do not manufacture the finished products; thus in general it may be inferred that two sets of freight charges, commissions and handling expenses are required before the products reach the consumer. For instance, with acetate of lime at $\$ 2.00$ the net return to the producer is about $\$ 1.75$ per hundred. A large part of this difference could easily be saved by manufacturing the finished product at the crude plants.

Hitherto such combinations of crude and finished product manufacture have been thwarted in the majority of cases by an almost complete monopoly of the finished products by certain groups of chemical manufacturers, who by various manipulations maintained control of markets, or who were able to dominate the situation, as in the case of acetic acid, by their regional control of sulfuric acid manufacture, or even attempted control of pyrites importation. The violent market fights which have developed because of these facts have been carried through successfully in more than one instance by the crude manufacturer, because of his advantageous situation and it is certain that these attempts, therefore, to thwart the natural economic development of this industry will sooner or later collapse to a great extent, or the refiner will be compelled to either go into the crude business himself or combine with the crude manufacturer.

We have attempted to show the difficulties met and the expensive experimentation that has been undertaken in the past for the improvement of this industry, and have pointed out some of the results thus obtained. When it is remembered that German statistics claim that but one of $I_{5}$ serious trials of new chemical processes are successful and that this percentage amply pays for the losses entailed in the I4 unsuccessful ones, it can be seen that while these expenditures are individually unfortunate, in the aggregate this law of averages will probably hold good in the development of this industry, for its economic position demands the solution of the problems indicated.

Columbus, OHIO

\section{DISCUSSION}

By H. О. Сhute

I am sure the thanks of the Institute are due Messrs. French and Withrow for this contribution to the history and present status in the U.S. of wood distillation and the presentation of the large number of illustrations showing actual present working plants.

While much has been previously published on this subject it has in most cases been by those familiar only with the European situation or who had been consulting European works of the subject.

It is a singular fact that most of the places named as sites of the first works still have working plants and the people and firms then engaged are still in the business. This indicates that the location of a wood distillating plant is not a temporary affair but that the wood supply usually lasts for a generation.

While the statement is true that the carbonization is an exothermic reaction yet the phenomenon is not observed unless the wood is fairly dry, i.e., with from I 5 to 20 per cent water. With excess of water the heat disengaged is not sufficient to evaporate the water so there is no progressive action toward the center of the retort except as produced by the fire, and the transmission of heat to the center of the retort from the walls is difficult. This shows the necessity of having dry wood for successful work. Owing to this exothermic reaction the control of the temperature inside the retort by any method of heat insulation or surrounding thermal baths is foredoomed to failure.

While the first operators brought over the Scotch methods yet later arrivals including Burcey, brought over the French methods as then and now practiced. The Burcey pans ate merely the French Pistorius pans used in the rectification of grain alcohol and the Otto plant of vertical retorts located at Sargeant near Dahoga, Pa., which has been described, was built by Burcey on the French system. These worked successfully for many years though they were never duplicated in this country.

It must be remembered that wood distillation in the U. S. has developed along two different lines. The charcoal iron industry was introduced at a very early period, in fact shortly after the settlement of the first colonists and this necessitated a supply of charcoal. No attempts to save any of the by-products were tried or accomplished till Dr. Pierce introduced his system of sucking off the smoke or vapors from the kilns with a fan and recovering the alcohol and acetate from them by condensation. With the large amount of charcoal necessary to supply the fur. naces and with wood plentiful and labor scarce it became advisable to use kilns; these can use green wood and wood in the form of logs and quite rough, while the retorts required the wood to be carefully cut and split to a six-inch face and dried for about a year. 
It is erroneous to state that a portion of the wood is burned in the kilns to support combustion as it is the gas which is evolved that is burned. This may be observed in an ordinary grate fire as the flame comes from the gas while the wood is not consumed till charcoal is formed which gives a flameless combustion. The Pierce system originally contemplated the forcing of the gas back into the kilns after condensation but it was soon found that the gas could not be circulated indefinitely, so that now the kiln is heated entirely by starting a fire inside it and admitting a regulated amount of air to burn a part of the evolved gases so as to generate the balance. For this reason the by-products are partially burned.

It may be said for the kiln process that while it produces only about one-half the amount of by-products it produces an equal quantity of charcoal and it produces more dollars in profits per dollar of investment than the retort process. It has been said that the western works do not produce a corresponding amount of acetate compared with the alcohol, but they do not distil the tar nor the acid as thoroughly as do the eastern works.

The original installation for sawdust carbonization at Cincinnati consisted of tall vertical narrow retorts much like those used for bone char work and with revolving cones inside attached to a central pipe perforated to allow the escape of the gases evolved. These were led out at the bottom but the outlet was soon closed with tar and charcoal dust. The idea of taking the gases out at the top never seemed to occur to the operators.

If any system of conveyors for carbonizing the sawdust was used it must have been well toward the end of the work. This installation was made at a cost of about $\$ 125$, ooo by one who had worked on the problem in Canada for a number of years and spent much money there. Every condition was favorable as the sawdust was from kiln-dried lumber, but the project was an absolute failure and should serve as a warning.

Shortly after 1900 the retort process was established in the west in connection with the sawmills. These sawmills working on hardwood will furnish about a cord of wood from the slabs and rough logs for every rooo $\mathrm{ft}$. of lumber sawed and the sawdust and offal will furnish enough fuel for the retorts and chemical works. When wood distillation is thus carried on as a by-product of lumbering operations it is evident that the cord wood will not cost $\$ 5.00$ per cord nor the fuel $\$$ I.I5 per cord, and these combination plants will therefore probably survive in the struggle for existence. The extreme conservatism of those connected with this industry is shown by the fact that nearly all the plants now use practically the same apparatus and methods that were introduced by the foreigners who first came over. The small round retort has, however, been superseded by the oven, those holding about ten cords each being most popular at present. These ovens are so built that the wood is handled in two-cord cars and the cars are usually handled by a locomotive in large works. The charcoal is also handled and cooled on the same cars and there is little breakage. Some improvement has been made in the west in the method of treating the liquors for alcohol and acetate. In 1905 a process was introduced for making alcohol by distilling the crude liquor in a continuous column still producing alcohol of 25 per cent strength from acid containing 2 per cent. On standing, the oils separated from this weak alcohol and an excess of alkali was then added which polymerized aldehydes and ketones. With another distillation through a similar continuous still it was possible to produce 85 per cent alcohol perfectly miscible with water. In I 906 a multiple effect evaporator was installed which was operated with exhaust steam from the blowing engine of the blast furnace and the acid was distilled in one vessel to purify it, then neutralized and run into the other for concentration; the heat of the condensing acid vapors furnished heat to evaporate the acetate solution.

These installations were made at Ashland, Wis., and the processes were covered by patents Nos. 824,906 and 835,501; shortly thereafter nearly all the kiln plants adopted the above method for producing alcohol and a number of them have also adopted the multiple effect process for handling the acetate. Of late years several modifications of these processes have been introduced but they have not yet operated a sufficient length of time to prove their worth.

It is a singular fact that although wood alcohol is always distilled over alkali, yet the ethyl acetate is only slightly decomposed as the so-called "acetone alcohol" or "methyl acetone" from the heads of the runnings will contain about 40 per cent acetone, 40 per cent methyl acetate and 20 per cent alcohol with specific gravity corresponding to 82 per cent alcohol and a boiling point of $55.5^{\circ} \mathrm{C}$. The presence of alcohol acts as a protective solvent.

In conclusion, it may be remarked that the American industry has reached a high state of perfection in the mechanical handling of materials and economical machinery. The production of wood alcohol and acetate has reached a state where more cannot be economically produced from a cord of wood. The quality of refined alcohol on the market is satisfactory and the highly refined grades are nearly C.P. The manufacture of such secondary products as acetone, formaldehyde and acetic acid is carried on successfully at some wood distillation plants.

The manufacture of formaldehyde has proved successful at some places. The manufacture of acetone should logically be at the works, thus saving freight as $5 \mathrm{lbs}$. of acetate are required for making a pound of acetone. Chemical engineering sometimes consists largely in the study of freight rates. The manufacture of acetic acid has been attempted at a number of works and abandoned though at least one plant still makes large quantities.

Acetate of lime is perhaps the most convenient method of shipping acetic acid and the manufacture nearer the market seems more logical.

The only product which is wasted is the tar. About $30,000,000$ gallons of wood tar are burned under boilers every year to get rid of it. Its utilization holds out as much promise as the utilization of coal tar, but with the exception of some light oils which are used in dissolving nitrocellulose there are no valuable products made. Yet we import nearly two-thirds of the creosoting oils we use for timber preservation and as it is probable that the wood creosotes are as valuable as the coal tar creosotes for this purpose, we may hope that this industry will soon develop.

197 Pearl StreEt, New York City

\section{INDUSTRIAL USES OF HYDROFLUORIC ACID'}

By K. F. STAHL

The larger works on Chemical Technology ${ }^{2}$ give the following uses for hydrofiuoric acid: ${ }^{3}$

I-Iiquid or gaseous hydrogen fluoride is used for etching glass. The liquid acid leaves a smooth transparent surface, while the gas leaves a rough opaque surface.

2-Hydrofluoric acid in connection with fluorides of the alkalies and some other additions, such as acetic acid or sulfuric acid and others, are used for frosting glass. For this purpose there is in general use a solution of acid ammonium fluoride in hydrofluoric acid. This has the trade name of "White Acid" and contains about 32 per cent $\mathrm{NH}_{4} \mathrm{FHF}$ and 20 per cent $\mathrm{HF}$. It works very quickly, e.g., the frosting of electric bulbs requires only about a minute.

1 Presented before the Pittsburgh Section of the American Chemical Society, October 15, 1914.

2 Dammer, Molinari, Ed. Thorpe and Henri Moissan.

3 It is generally known that hydrofluoric acid produces very painful inflammation if allowed to come in contact with the skin. The remedy usually recommended is washing with water and then with dilute ammonia water. This is effective only with weak acids; with stronger acids, particularly the 60 per cent, washing alone, even if done immediately, does not prevent inflammation, but if the washing is continued for about half an hour by holding the affected part under flowing water the bad effects will be prevented or at least materially reduced. Washing must, of course, begin at once after the acid has come in contact with the skin. Very dilute acid, $i$. e., up to 5 per cent, produces no ill effect by temporary contact with the skin. 